\title{
Optimization of the traffic light regulation parameters on the urban road network in order to minimize the negative environmental impact
}

\author{
Konstantin Katerinin ${ }^{1}$ and Bulat Sanzhapov ${ }^{1^{*}}$ \\ ${ }^{1}$ Volgograd State Technical University, 400074, Volgograd, Russia
}

\begin{abstract}
A large number of vehicles in cities has a significant negative impact on the environmental situation. Today, economic measures are actively applied to reduce the number of vehicles used with internal combustion engines, and new technical solutions are being introduced to reduce exhaust toxicity. However, the potential of these approaches to improving the environmental situation in cities is very limited and has already been almost fully realized. Therefore, the huge potential to minimize environmental damage, in an increasing number of vehicles in large cities, is to optimize the parameters of traffic flows. The key role here is played by the scheme of traffic light control, to the consideration of the optimality parameters of which this work is devoted.
\end{abstract}

\section{Introduction}

Road transport has a huge impact on the ecology of the urban environment. This is confirmed by expert estimates of environmental monitoring data of urban areas, and it is not only about emissions of combustion products of motor fuel. Fine rubber dust, which is a product of the natural abrasion of tires, is a dangerous carcinogen that adversely affects the overall environmental safety of the urban environment. The same can be said about the abrasion of the brake pads of cars - although their composition is no longer used asbestos, harsh operating conditions do not allow to use for their manufacture only environmentally friendly materials.

It should be noted that for the same volume of traffic, the amount of the abovementioned harmful emissions may vary significantly depending on the traffic flow regime. The greatest influence here is the number and intensity of cycles of acceleration and deceleration of the traffic flow in the considered section of the urban road network. At the same time, it is the number of such cycles that has a greater impact, and not the total idle time of transport on the prohibiting traffic light signal. Indeed, more and more modern cars are now equipped with a "start-stop" system that turns off the engine at each stop, and starts it only at the start of the movement. Electric cars also appear on the roads of cities, and the total share of such environmentally friendly transport is steadily growing. However, the abrasion of tires and brake pads is not affected, and the only way to minimize these negative environmental processes is to optimize the organization of traffic in the city.

* Corresponding author: sbkh@mail.ru 


\section{Objective and tasks of research}

Most of the time, transport in the city moves along major highways, stopping at small streets or yards only at the beginning or at the end of the road. Transit traffic on secondary roads is inconvenient due to their tightness, poor visibility, an abundance of unregulated pedestrian crossings, therefore, most drivers prefer to move the main roads of cities. All intersections on such roads are equipped with traffic lights, and the parameters of their switching just form the basis on which the entire structure of urban traffic is built.

Thus, the main role in the issue of "environmental friendliness" of the adopted traffic organization scheme is played not by the time of switching cycles of each individual traffic light, but by the General interconnected scheme of their work. This scheme should ensure, first of all, the greatest smoothness of the mass traffic flow along the main urban highways, with a minimum of its projected stops at traffic lights. As noted above, each cycle of acceleration and braking of transport is negative from the point of view of ecology, so minimizing the number of such cycles on the main highways of the city is an environmental priority.

\section{Review of the methods of solving the problem}

To solve this problem, it is possible to use a variety of approaches, from approximate graph-analytical modeling to computer simulation using various software products and algorithms implemented in them. It is important to determine what should be considered the criterion of optimality of the developed scheme of traffic light regulation. On the one hand, it may seem that the main indicator may be the estimated capacity of highways, and the higher it is, the better. However, if the scheme is configured to cause frequent stops at a stoplight, it cannot be considered optimal from an environmental point of view, even at outstanding throughput rates.

The so-called "green wave" is a well-known, simple and effective way of forming a smooth road traffic flow, when traffic lights are switched on so that a car moving at a certain speed always gets a green signal. This is a kind of ideal model, it is easy to analyze and organize and has been known and popular in large cities since the 50s of the last century. Its problem lies in the fact that with a large congestion of roads, almost a very small percentage of transport is able to move in this mode, and most do not have time to gain the desired speed and have to stop at almost every traffic light, which is why in today's realities the whole meaning of this scheme is lost. 


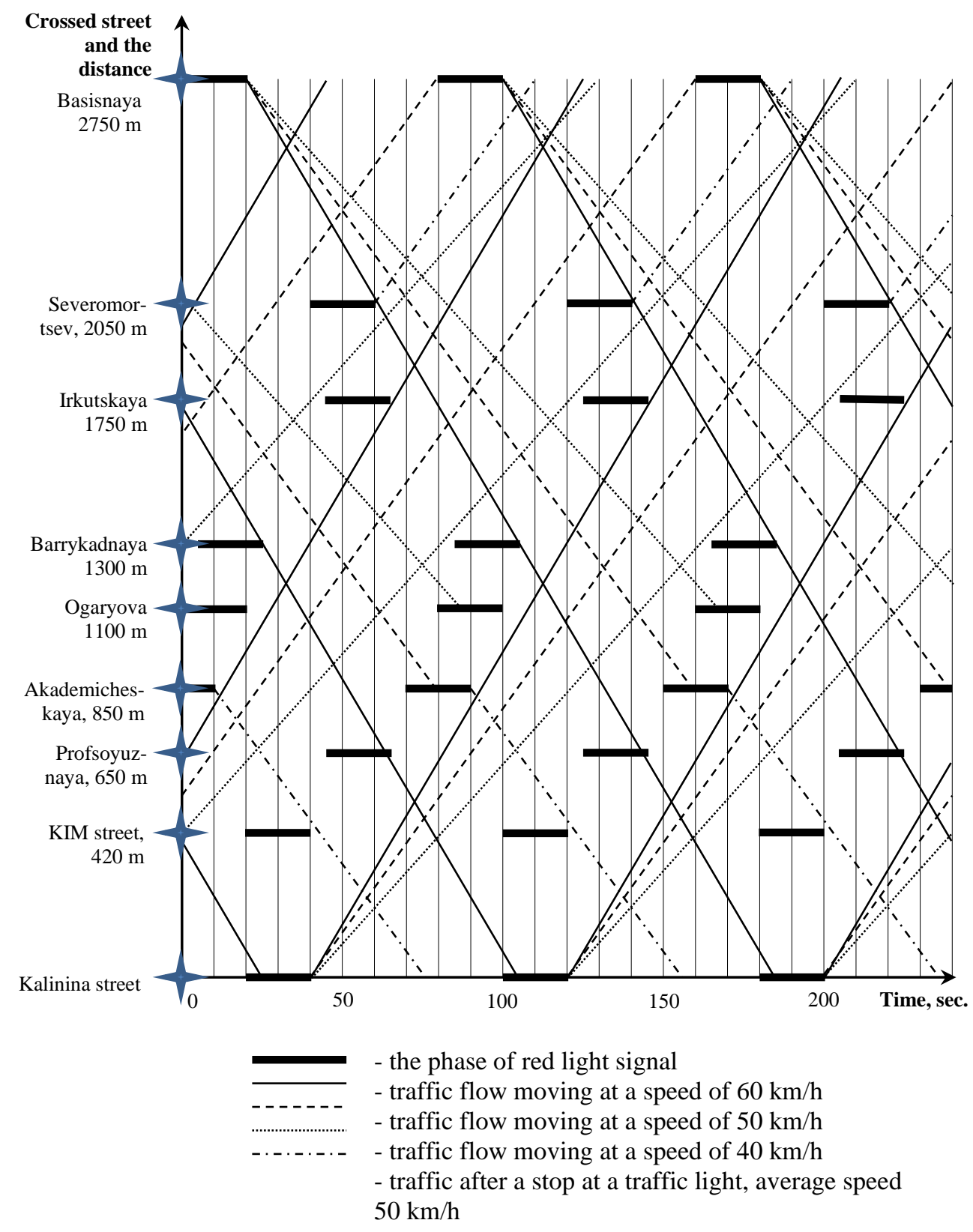

Fig. 1. Optimized scheme of traffic light regulation on Raboche-Krestyanskaya street, Volgograd, Russia

\section{The proposed method of solving the problem}

As an alternative, it is proposed to build a scheme of traffic light regulation on the basis of the following logical postulates.

1. The vehicle that started the movement, when switched on the green light, should be able to have time to go through the next traffic light to turn on the red light. 
2. There is no need to organize a "green wave" throughout the highway. The priority is the organization of separate sections of non-stop traffic, in the places of docking of which there is a stop at the prohibiting traffic light signal.

3. Places for such planned traffic stops should be specially designated so that they do not fall into undesirable zones. These include parking spaces, public transport stops, etc.

To develop and analyze the traffic light control scheme, it is proposed to use a twodimensional graphic-analytical scheme, where one of the axes shows the distance between all available traffic lights, and the other, the time axis, shows the phases of the green and red (black fat line) signals of each traffic light in a time relationship. The traffic flow is modelled by an inclined line, the angle of inclination of which is directly proportional to the speed of the vehicle. In this case, the modeling problem is reduced to a graphical selection of such signal durations and initial phase shift of each traffic light, so that the process of traffic flow is most consistent with the above rules. As illustration, we present is designed according to these principles, the scheme of organization of traffic regulation (Fig. 1) along the Raboche-Krestyanskaya street (Volgograd, Russia).

\section{Conclusion}

The goal of this study was to obtain a simple and visual tool for the analysis of existing or projected traffic light control scheme on a city street. The proposed method of graphical analysis for compliance with the criteria of optimality of the traffic light control system allows you to quickly and clearly analyze and, if necessary - optimize its parameters. As a result, environmental damage to the urban environment is minimized, and also creates a safe and psychologically comfortable for drivers mode of movement through the streets with a minimum number of stops at traffic lights.

\section{References}

1. K. Katerinin, Bulletin of Volgograd State University of Architecture and Civil Engineering, 47, 220-234 (2017).

2. B. Sanzhapov, Polymodal expert estimates, J. of Computer and Systems Sciences International, 33 (5), 161-165 (1995).

3. B. Sanzhapov, Multimodal expert estimates, Izvestiya Akademii Nauk. Teoriya i Sistemy Upravleniya, 2, 213-218 (1994).

4. B. Sanzhapov, R. Sanzhapov, ARPN Journal of Engineering and Applied Sciences, 11 (13), 8544-8548 (2016).

5. B. Sanzhapov, A. Sinitsyn et al., Procedia Engineering, 150C, 1948-1953 (2016).

6. B. Sanzhapov, R. Sanzhapov, ARPN Journal of Engineering and Applied Sciences, 12 (15), 4601-4607 (2017).

7. B. Sanzhapov, N. Rashevskij, A. Sinicyn, International Conference on Construction, Architecture and Technosphere Safety (ICCATS 2017), Chelyabinsk, Russian Federation (2017).

8. D. Likhachev, Towards the issue of traffic capacity of regulated crossroads, Problems of vehicle quality and operation, 241-246 (2016).

9. A. Shevtsova, I. Novikov, A. Borovskoi, Information technologies and transport innovations, 366-370 (2016).

10. E. Evdokimov, D. Senkin, D. Sil'chenkov, Energy and resource-saving: industry and transport, 6 (166), 47-50 (2015). 